\title{
A Contribuição da Controladoria no Processo de Gestão Organizacional
}

\section{The Controllership Contribution in the Process of Organizational Management}

\author{
Ayron Vinícius Pinheiro de Assunção*aa Daniel Massen Frainer ${ }^{\text {b; }}$ Michelle da Rosa Lopes ${ }^{\mathrm{a}}$; Eduardo Henrique Zanão ${ }^{\mathrm{a}}$
}

${ }^{a}$ Centro Universitário Anhanguera de Campo Grande. MS, Brasil.

bAnhanguera - Uniderp. MS, Brasil.

*E-mail: ayron.assuncao@anhanguera.com

\begin{abstract}
Resumo
A decisão é muito importante dentro de uma organização, para isso, a Controladoria e o Controller contribuem para uma gestão organizacional eficiente, e este estudo procura demonstrar a missão, a função, o papel e a competência do Controller em uma empresa. A Controladoria pode contribuir como ferramenta de gestão, pois através dos relatórios elaborados é possível aos gestores um melhor controle e planejamento da organização, assim como na elaboração e execução dos projetos, principalmente os operacionais, tendo em vista o controle de curto, de médio e de longo prazo. Uma estrutura organizacional bem desenvolvida necessita de um excelente gestor para a tomada de decisão, contudo, os departamentos precisam criar relatórios detalhados para que o mesmo tenha uma ampla visão do desempenho da entidade. A Controladoria é uma área que necessita ser desenvolvida por um profissional habilitado e com muita competência, devendo se manter atualizado, o que possibilitará ao mesmo o diagnóstico preventivo de problemas e a proposição de soluções. A competitividade nos grandes mercados exige uma gestão enxuta, pois tudo impacta nos preços e na qualidade dos produtos/serviços oferecidos e o sucesso da organização vai depender do seu nível de eficiência na produção, dessa forma, o processo de Controladoria pode contribuir para a otimização da produção, oferecendo ferramentas para um menor nível de desperdício.
\end{abstract}

Palavras-chave: Competência. Planejamento. Organização.

\begin{abstract}
Decision is very important in an organization. Thus, For this, the Controller and Controllership Controller and Controller contribute to an efficient organizational management, trying to demonstrate the mission, role, and competence of the Controller in a company. Controllership can contribute as a management tool, because through the reports elaborated it is possible for the managers to better control and plan the organization, as well as in the elaboration and execution of the projects, mainly the operational ones, in view of the control of short, medium and long term. A well-developed organizational structure needs an excellent manager for decision making, but departments need to create detailed reports so that they have a broad view of the organization's performance. Controllership is an area that needs to be developed by a qualified professional and with a lot of competence, and must be kept up to date, which will allow preventive diagnosis of problems and the proposition of solutions. Competitiveness in large markets requires lean management, since everything impacts on the prices and quality of the products / services offered and the success of the organization will depend on its level of efficiency in production, and thus, the Controlling process can contribute to the optimization of offering tools for a lower level of waste.
\end{abstract}

Keywords: Competence. Planning. Organization.

\section{Introdução}

A pesquisa científica inicialmente apresentará o conceito, a função e o papel da Controladoria, a seguir será definida a função do Controller e, para finalizar, será apresentada qual a contribuição da Controladoria e sua importância para o futuro da organização.

Diante da necessidade das empresas de uma ferramenta que possibilite o conhecimento da qualidade das funções operacionais, com a apresentação de dados que auxiliem na tomada de decisão eficaz garantindo a continuidade da organização, é possível verificar que a Controladoria pelo fato de ser formada de diversas áreas de conhecimento é essencial para atender a essas necessidades, facilitando a gestão de informações.

Porém, tanto a Contabilidade quanto a Controladoria necessitam de profissionais altamente qualificados, que no seu âmbito de trabalho possam expor sua capacidade dentro de sua área, demonstrando desenvoltura em relação ao planejamento, execução e controle da organização, a fim de obter excelentes resultados.

Com a ampliação das transações de dados e o modo das operações, a responsabilidade da Contabilidade e Controladoria aumentou, modificando drasticamente a visão de controle organizacional. Com isso, as multinacionais resolveram trazer suas experiências para implantar nas empresas brasileiras.

O Controller é a pessoa incumbida pela área de Controladoria de apresentar informações econômicas, financeiras e gerenciais em uma organização, em que além do domínio destas áreas, é preciso que o mesmo esteja atento às modificações externas que a organização possa sofrer, vislumbrando garantir que as informações sejam tempestivas 
e pertinentes, e que seja ainda capaz de visualizar prováveis riscos de mercado no qual a organização está inserida.

As funções são diversificadas de acordo com cada entidade, dependendo do sistema organizacional que é estabelecido dentro da mesma, sendo que deve haver um grande controle nos procedimentos da área administrativa e produtiva.

O objetivo dos gestores é ampliar o aspecto de suas transações para a empresa sobreviver no mercado, devendo atuar em sua reorganização em caso de crise financeira e, para isso, a Controladoria tem papel fundamental, pois a mesma proporciona aos gestores análises técnicas e confiáveis para uma melhor tomada de decisão.

\section{Desenvolvimento}

\subsection{Metodologia}

Pesquisa foi realizada em referências bibliográficas, com o objetivo de verificar: A Contribuição da Controladoria no Processo de Gestão Organizacional.

\subsection{Discussão}

\subsubsection{Controladoria}

A controladoria surgiu no início do século XX em um momento de mudanças, durante a revolução industrial, nas grandes companhias norte-americanas, com o intuito de promover um rigoroso controle, pois não havia quem o fizesse nas matrizes e filiais.

Definida como ciência autônoma e que não se deve confundir com a Contabilidade, apesar da utilização das informações contábeis, e pode ser definida como a responsável pela unidade administrativa pela utilização de todo conteúdo do conjunto da Ciência Contábil em uma empresa.

A ciência Controladoria pode ser entendida, ainda, como a evolução contábil e como área de conhecimento possui uma alta responsabilidade na construção e na manutenção do sistema de informação da gestão da entidade, pois é responsável por gerar as informações adequadas para a tomada de decisão. Assegurando-se sempre pelo princípio da continuidade e a procura de um excelente resultado.

Para obter um eficiente trabalho, o Controller necessita de um bom entendimento de toda área administrativa e deve estar por dentro de tudo que envolve o mercado financeiro, contudo, atualizar-se é a melhor maneira para que nenhum dado seja esquecido ou mesmo fique fora dos padrões contábeis.

Pasoveze (2015, p.33) definiu a Controladoria como:

Controladoria é a unidade administrativa dentro da empresa que, por meio da Ciência Contábil e do Sistema de Informação da Controladoria, é responsável pela coordenação da gestão econômica do sistema da empresa.

Para Wahlmann (2003, p.11):

A Controladoria constitui uma área de Ciências Contábeis composta por um conjunto de conhecimentos interdisciplinares oriundos da Administração de Empresas, Economia, Informática, Estatística e, principalmente da própria Contabilidade.

Neste caso, esse autor vê a Controladoria como uma área da Contabilidade e da mesma forma que a área de custos, gerencial, financeira e outras correlatas.

Padoveze (2015) considera que a Controladoria é a utilização da Ciência Contábil em toda a sua plenitude. Dessa forma, o autor sustenta seus argumentos e tem a certeza de que a controladoria é uma inovação e evolução da Contabilidade, e sendo uma ciência social é preciso uma atualização, conforme a necessidade das empresas.

Portanto, verificando o entendimento e a opinião de cada autor se pode verificar que alguns se sujeitaram a divulgar e estabelecer o conhecimento de forma clara e objetiva, conforme a referida dificuldade que o assunto pede, fica complicado analisá-la por causa da utilização de diversos instrumentos operacionais.

O Controller tem como papel é de monitoramento do plano de ação da empresa, fazendo a avaliação coordenada da atuação de todos os gestores, sempre com foco no desempenho e resultados, global e setorial. É importante ressaltar que ele não é responsável pelo alcance dos resultados planejados (PADOVEZE, 2015, p. 36).

A Controladoria mostrará informações para agregar aos controles, confirmando e comprovando os custos e as receitas dos resultados operacionais, guiando a organização de sua missão institucional.

\subsubsection{Funções da Controladoria}

A controladoria tem por finalidade assegurar a eficácia da empresa, por meio da otimização de seus resultados, auxiliando as áreas de atuação, em que se pode colocar os conhecimentos em uma gestão organizacional.

Conforme Padoveze (2015) se pode explicitar a missão da Controladoria: dar suporte à gestão de negócios da empresa, de modo que assegure que esta atinja seus objetivos, cumprindo assim sua missão. Tratando-se disso se têm as principais funções e suas respectivas missões:

$\checkmark$ Planejamento: elaboração de um projeto com o intuito de alcançar os objetivos almejados.

$\checkmark$ Organização: para que esse objetivo seja atingido é essencial uma excelente estrutura organizacional.

$\checkmark$ Direção: estabelecer a divisão de tarefas, obedecendo à gestão.

$\checkmark$ Controle: medidor do trabalho executado com relação ao propósito da entidade.

$\checkmark$ Informação: compreender os sistemas contábilfinanceiro-gerenciais.

$\checkmark$ Coordenação: visa centralizar informações com vista na aceitação de planos. O Controller toma conhecimento de eventuais inconsistências dentro da empresa e assessora a direção, sugerindo soluções.

$\checkmark$ Avaliação: interpreta fatos, informações e relatórios, avaliando os resultados por área de responsabilidade, por processos, por atividades etc.

$\checkmark$ Acompanhamento: verifica e controla a evolução e o desempenho dos planos traçados, a fim de corrigir falhas ou de revisar tais planos.

Portanto, essas funções são constatadas em toda 
organização, estando praticamente no dia a dia da controladoria para elevar a efetividade da entidade. Enfim, esse controle se transformou em um excelente plano estratégico em um mercado cada dia mais rigoroso e competitivo.

\subsubsection{Papel e objetivo da Controladoria}

O processo decisório é induzido pela atuação da Controladoria no planejamento e controle, resultantes das informações passadas aos gestores.

O assessoramento com informações para tomada de decisão exige um sistema de informações de planejamento e de controle. A Controladoria, através do modelo de gestão, otimiza os resultados econômicos da empresa por meio da definição de um modelo de informação.

O papel da Controladoria é de assessorar diversos níveis de gestão dentro da empresa, disponibilizando alternativas econômicas mensuradas e, por meio da observação sistêmica, reunindo e integrando informações e as passando à frente para facilitar o processo decisório. Diante disso, a influência exercida pelo Controller na organização, à medida que direciona os gestores, propicia com que que mantenham a organização no processo eficaz de resultado e de crescimento.

Conforme Padoveze (2005), o objeto da Ciência da Controladoria é o controle econômico das entidades, portanto, é uma gestão baseada em resultados econômicos.

No controle, é de responsabilidade do gestor contábil exercer a função de perito ou juiz, analisando os fatos e, conforme os casos, de forma independente, assessorando na conclusão dos números e das métricas qualitativas e quantitativas (índice de qualidade).

Controladoria como órgão provedor de informações e complementar de uma corporação organizacional é orientada a observar e controlar as consequências dos atos da administração econômica interna, acompanhando os resultados para que aconteçam e se desenvolvam de forma a prover a empresa de valores, mantendo assim continuidade da entidade.

É explícito que o objetivo da controladoria é obter meios para que o funcionamento da empresa possa ser verificado e avaliado, mas para isso é necessário observar e analisar as atividades de outras empresas, a fim de demonstrar ao gestor um parâmetro para o caminho da busca das melhorias nos resultados.

A Controladoria não pode ser apenas um método contábil, envolve todo o processo sistêmico para a gestão organizacional, iniciando pelo planejamento e finalizando com o controle efetivo das operações, ratificando assim uma coleta de dados importante para o desenvolvimento da missão, com a responsabilidade de agrupar e de disponibilizar o máximo de informações para que o gestor possa tomar decisões assertivas.

\subsubsection{Sistemas de Informações}

Nas últimas décadas, o mundo se tornou cada vez mais aberto e acessível. A movimentação dinâmica dos negócios e do mundo leva a novos horizontes para a médias e grandes empresas. Essas transições que ocorrem levam ao aprendizado de que se está recebendo muitas informações e tendo transformações significativas no mundo empresarial. Isso impõe a necessidade de constante correção e de prevenção e de reinvenção, consequentemente, traz novos problemas gerenciais. Portanto se faz necessária alguma atitude diferente daquela que se tem no dia a dia que é, na verdade, apenas manter as coisas como essas estão. O mundo empresarial está passando por transições visíveis e importantes. O aprendizado constante e inovador se tornou inevitável para as organizações, que pretendem competir de forma eficiente e eficaz no atual ambiente empresarial.

As empresas que não captarem as modificações, mudanças e informações pertinentes ao que está acontecendo, no ambiente em que estão inseridas, estarão perdendo campo para outras mais antenadas e preparadas na compreensão da gestão e da informação.

As empresas que sempre conseguiram vencer pelo seu tamanho perdem espaço para suas concorrentes mais ágeis no uso da informação. Empresas dotadas de percepção do negócio e dotadas de feeling passaram a compreender que para conseguir ser mais ágil e eficaz se faz necessário um sistema de informações eficiente, inserido na controladoria.

Segundo Padoveze (2015; p. 46) diz que:

$\mathrm{O}$ atual ambiente tecnológico tem apresentado como solução para a maior parte dos sistemas de informações necessários para as empresas o conceito de Sistema Integrado Empresarial. São assim denominados os sistemas de informações gerenciais, que têm como objetivo fundamental a integração, consolidação e aglutinação de todas as informações necessárias para a gestão do sistema da empresa.

A controladoria, como órgão administrativo, tem por objetivo fornecer informações úteis ao processo decisório, assegurando a eficiência do seu sistema de informações.

Segundo Padoveze (2015, p.45):

Podemos defini-lo como um conjunto de recursos humanos, materiais, tecnológicos e financeiros agregados dos segundo uma sequência lógica para o processamento dos dados e tradução em informações, para com o seu produto, permitir às organizações o cumprimento de seus objetivos principais.

Ratificando que a Controladoria sempre estará presente no processo de execução, como poderosa ferramenta, capaz de auxiliar na aprendizagem organizacional e nos sistemas de informações.

O sistema de informações de acompanhamento do negócio é a necessidade da empresa tem de acompanhar o que está acontecendo no mercado, situar na conjuntura econômica do País e do exterior. O negócio é acompanhado pela reunião de informações do ambiente interno e externo, suas ameaças e enfatizando os pontos fortes e fracos da companhia. 
O armazenamento de informações ocorre pelo sistema de integração entre a coleta e armazenamento de informações, que vão possibilitar a visualização da empresa em relação ao seu ramo de atuação.

A informação no tempo certo, precisa e com geração de valor, deixa o gestor munido para tomada de decisão e consequente atuação no processo econômico da empresa, fazendo com que os ganhos sejam maiores e mais consistentes, isso promove a competitividade da empresa no mercado interno e externo.

\subsection{Função do Controller}

O Controller, nos tempos atuais, de mudança e de informação instantânea, deve ser um profissional que exerça atuação multifuncional, ou seja, deve atualizar e acumular conhecimento e experiências nas áreas contábeis, financeira e administrativa. É um papel destinado ao profissional da controladoria, que tem a função de exercer informações gerenciais, econômicas e financeiras da organização, garantindo que essas sejam confiáveis e levadas até aos gestores em tempo adequado.

Para que as tarefas da controladoria sejam efetivas, o controller deve, segundo Oliveira, Perez Junior e Silva (2005):

a) adequar controles internos; b) analisar a eficiência dos sistemas operacionais; c) sugerir melhorias para a redução de custos; d) verificar o cumprimento dos planos e objetivos traçados pela organização; e) analisar as causas de desvios e sugerir correção desses planos ou dos instrumentos e sistemas de controle; f) analisar a adequação na utilização dos recursos materiais e humanos da organização; g) revisar e analisar os objetivos e métodos de todas as áreas da organização.

O profissional deve estar atento às mudanças, que ocorrem diariamente, ter conhecimento em gestão organizacional, de recursos humanos, estoque, financeira e produção, possuir visão holística do negócio, empresas buscam profissionais multifuncionais que se sintam como donos do negócio, com isso, a dedicação ao trabalho é fundamental para que tenha sucesso.

Esse conhecimento vem de um controle preciso e constante dos indicadores da empresa, sendo necessário que tenha certa independência, estando diretamente ligado aos gestores.

O Controller precisa ter a capacidade de prever os problemas que surgirão e coletar as informações necessárias para tomada de decisão, assumindo o papel de conselheiro e de crítico (sentido construtivo) do processo, visando implantação de ações de melhorias, não deve ser omisso ou displicente nas informações, ser ágil e constante no processo de prover os gestores de informações corretas.

Dessa forma, o Controller responde o que as empresas vêm buscando, que é um profissional com competências e a disposição de assumir esse papel de visão futura, olhar crítico e otimista em seu resultado, gerando a intenção de melhoria da empresa.
O controller pode e deve exercer influência junto aos demais gestores e o faz pelo conhecimento da ciência da gestão econômica. Em outras palavras, o conhecimento da empresa como um todo e o conjunto dos planos de ação, associados ao conhecimento científico da administração, permitem ao profissional de controladoria exercer um papel influenciador (PADOVEZE, 2003, p. 36).

Encarregado pelo departamento de controladoria, seu papel é gerir um eficiente sistema de informação, conciliando as atividades desenvolvidas para alcançar os resultados esperados e cuidando pela continuidade da empresa.

O Controller é um profissional com competências para analisar todas as informações necessárias, como: taxas, investimentos, resgates, despesas, custos, empréstimos, riscos entre outros. Tendo assim pleno conhecimento da vida financeira da organização.

A facilidade em visualizar os pontos negativos e positivos da organização, incluindo analisar as demonstrações de relatórios financeiros para assim sugerir modificações para melhorias e o desempenho das áreas envolvidas.

Diante dessas facilidades, o Controller liga a direção e o restante da organização, pois ele se depara com situações, nas diversas áreas da organização, tendo que proporcionar para adireção as mudanças que devem ser realizadas para obtenção de melhores resultados e fazer com que estas mudanças sejam aceitas e se difundam de forma positiva entre os colaboradores.

O moderno profissional da controladoria terá que dominar conhecimentos de administração geral, sociologia, finanças, marketing etc. além, evidentemente, de contabilidade, custos e tributos. A preocupação com eficácia, com resultados práticos e lucratividade pode motivar uma ênfase exagerada nos conhecimentos práticos, em prejuízo de um bom embasamento teórico. É necessário, no entanto, buscar equilíbrio e lembrar o valor da teoria para desenvolvimento do ser humano (OLIVEIRA; PEREZ JUNIOR; SILVA, 2005 p. 27).

Para tanto, o Controller acaba sendo o responsável pelo projeto, implementação e manutenção de um sistema integrado de informações, que operacionaliza o conceito da controladoria como principal instrumento.

Segundo Atkinson et al. (2000), controller é a figura de um executivo sênior de finanças e Contabilidade que organiza e realiza as interpretações das informações financeiras para os administradores, investidores e credores.

Segundo Figueiredo (2004, p.29), a controladoria está envolvida com a busca pela eficácia organizacional; para alcançar, é necessário que sejam orientados com modelos eficientes que conduzam ao cumprimento de sua missão.

A Controladoria está diretamente integrada com todas as áreas de uma organização. E é através da elaboração e do acompanhamento de relatórios gerencias, econômicos e financeiros, que auxilia e possibilita aos gestores uma maior confiabilidade e segurança na tomada de decisão. Portanto, é fundamental que a empresa possua uma estrutura de controle eficaz e que possa ser disseminado na mesma como um todo, de forma clara e concisa, potencializando o desempenho por 
intermédio de seu processo de gestão e conduzindo à eficácia organizacional.

Deixando claro que o principal objetivo da controladoria é obter informações e agrupá-las através de dados para que, dessa maneira, possa propiciar um suporte tempestivo, visando subsidiar o processo decisório empresarial para a busca de melhores resultados. Com a intenção de que a empresa atinja sua missão, sua visão e seus objetivos, e assegurando aos tomadores de decisão uma maior margem de confiabilidade e menor possibilidade de erros previsíveis, para não expor a organização a riscos de curto, médio e longo prazo.

A Controladoria tem como missão suportar todo o processo de gestão empresarial por intermédio de informação, que é um sistema de apoio à gestão. O sistema de informação da Controladoria é integrado com os sistemas operacionais e tem como característica essencial a mensuração econômica das operações para planejamento, controle e avaliação dos resultados e desempenho dos gestores das áreas de responsabilidade (PADOVEZE, 2015, p.36).

A controladoria é um papel de gerenciamento que deve ser desenvolvida por profissional contábil capacitado e com uma visão ampla. A busca contínua por atualização, inovações e mudança de cultura e por novas soluções são apenas o começo de um caminho para quem pretende seguir neste mercado.

Outro propósito importante da controladoria é criar, estruturar ou adaptar um sistema na estrutura organizacional da empresa, confirmando que as suas informações sejam relevantes, no que diz respeito ao caminho mais adequado para chegar aos resultados almejados. É através dela que seus usuários passam a ter informações fidedignas, com veracidade e em tempo hábil.

\subsection{A Controladoria com enfoque ao futuro da organização}

Vivencia-se um novo cenário em que o mercado está cada vez mais competitivo, exigente e com grandes avanços tecnológicos. Com isso, as organizações passaram a se preocupar com os processos de gestão dentro de suas companhias, como busca da garantia de continuidade e de crescimento, sendo fundamental e necessário que a empresa possua uma estrutura organizacional bem projetada e adaptável às mudanças e aos avanços do mercado, no qual está inserida.

A modernização das organizações, o alcance de seus objetivos de lucro, de produtividade, o seu nível de qualidade e de sua competitividade requerem um repensar da função da organização (AGUIAR, 2002, p.279).

Os gestores devem possuir uma visão ampla, pois são eles os responsáveis pelas decisões presentes e futuras e, principalmente, pelo andamento dos negócios. Sendo assim, estes são os principais interessados nas demonstrações contábeis da empresa.

Os relatórios elaborados pela controladoria devem permitir que os gestores tenham uma linha de informação contínua, sobre diversos ângulos voltados à gestão financeira, econômica e patrimonial da organização, esses relatórios devem possibilitar uma maior visão sobre os objetivos e as metas já alcançados, e subsidiar o planejamento necessário a ser realizado para que se possam atingir os resultados esperados. Através destes relatórios se deve permitir, por meio de projeções dos dados contábeis, a influência nas tomadas de decisões.

Para tanto, a controladoria empresarial é de suma importância para a sobrevivência da organização, sendo uma norteadora de possíveis rumos a serem traçados. Consubstância-se devido ao fato de poder mensurar e ter a possibilidade de prever possíveis erros capazes de trazer riscos e de afetar a continuidade da organização.

A Controladoria é voltada para geração de valores dentro da empresa, por registrar, informar, controlar e otimizar. A otimização dos resultados por partes, cada setor otimizando o seu, não consegue realizar o todo, porém a Controladoria consegue otimizar valores globais, contribui para a missão da empresa, ajuda a empresa a ganhar dinheiro.

Única área da empresa que atende a três requisitos para otimização do lucro global é isenta das demais atividades, possui conhecimento e instrumentos de gestão, sendo focada para alcançar os objetivos e precisa classifica e integrar ao processo de gestão.

A indução é como a controladoria age hoje, induzido aos processos e de geração de valores e de informações necessárias e precisas para a tomada de decisão.

A sinergia e a otimização isolada das partes não conduzem ao otimismo total que deve ter entre todos os departamentos, que é primordial, a interação e integração dos departamentos na geração de valores para empresa, pois todos estão direcionados ao objetivo principal da empresa.

A informação é a matéria-prima para uma tomada de decisão, por isso, com a otimização e a interação das partes para o objetivo da empresa fica mais fácil e confiável para que o gestor tome as devidas providências dentro da empresa.

A filosofia de atuação da controladoria, na coordenação de esforços visando sinergia das ações, participando e apoiando as áreas operacionais.

A indução as melhores decisões para a empresa são geradas pela credibilidade e são aspectos motivacionais para todos na empresa.

A Controladoria deve possuir dois instrumentos:

- Sistema de Informações.

- Sistema de orçamentos.

Sistema de informações envolve que a empresa deve possuir, orçamento, simulações, os resultados realizados, o desempenho e o gerencial.

Orçamento é muito importante dentro da empresa, demonstra o que a empresa quer buscar, junto com o orçamento a empresa também deverá possuir um sistema de simulação, um simulador de situações para que o que foi planejado seja 
verificado antes que gere um resultado negativo.

No desempenho será avaliado como se faz o processo de avaliação de desempenho.

O gerenciamento é o que está ligado com a gestão, o bom gerenciamento leva a uma boa performance no mercado interno e externo.

Tudo se inicia no planejamento, o plano de estratégias montado pela diretoria é o que vai guiar a corporação no objetivo que deseja e em executar o que foi planejado. Para realizar o planejamento, a empresa deverá possuir um banco de dados do ambiente interno e externo da empresa.

Dentro de uma visão de gestão econômica, o planejamento é muito importante para escolha das alternativas e das diretrizes, em que se têm simuladores de preços, mix e previsão, depois se segue para o detalhamento do planejamento.

Um sistema de orçamento vai ser usado na execução. Com isso, o Controller consegue monitorar a execução, comparando o planejado com o que está sendo operacionalizado.

A fase de controle faz o acompanhamento do realizado, observando e avaliando o desempenho, conforme o planejado.

O controle é quando se têm o plano e as metas, as empresas de grande porte já se utilizam dos meios de controles.

\section{Conclusão}

A Controladoria é capaz de conhecer o ambiente no qual a organização está inserida, pois o ambiente e suas forças, internas e externas, influenciam na base de sua estrutura organizacional, e devem propiciar com que os planos de ação e disposição de recursos, os quais a mesma dispõe sejam fortemente estruturados na busca de competitividade e na produção de valor crescente, interagindo diretamente com o mercado em que atua.

Dessa forma, cabe a controladoria a responsabilidade pela coordenação da gestão econômica do sistema organizacional, ou seja, cabe a esse setor dar suporte para a gestão dos negócios, assegurando sua eficácia, com a maximização de seus resultados, permitindo que esta coordenação seja clara e defina o caminho em que ela está e qual o caminho que deve seguir.

Conclui-se que é de fundamental importância que as empresas possuam um sistema interno, cujo principal objetivo seja a garantia de informações tempestivas e pertinentes ao processo decisório organizacional com a perspectiva de assessorar os gestores com dados capazes de aprimorar todas as ações realizadas, contribuindo para o crescimento da organização, sendo a Controladoria, desde que bem estruturada, a peça chave para orientar os rumos a serem traçados para que a organização atinja sua finalidade social, baseada em sua missão, visão e valores.

\section{Referências}

AGUIAR, M.A.F. Psicologia aplicada à administração: globalização, pensamento complexo, teoria crítica e a questão ética nas organizações. São Paulo: Excellus, 2002.

FIGUEIREDO, S. Controladoria: teoria e pratica. São Paulo: Atlas, 2004.

PADOVEZE, C.L. Controladoria estratégica e operacional. São Paulo: Thomson, 2003.

PADOVEZE, C.L. Controladoria avançada. São Paulo: Pioneira Thonson Learning, 2005.

PADOVEZE, C.L. Controladoria estratégica e operacional: conceitos, estruturas, aplicação. São Paulo: Ceange Learning, 2015.

PEREZ JÚNIOR, J.; PESTANA, A.O.; FRANCO, P.C. Controladoria de gestão: teoria e prática. São Paulo: Atlas, 2005.

WAHLMANN, G.C. Um estudo exploratório sobre a atividade de controladoria nas microempresas na cidade de Ubatuba. Caraguatatuba: Faculdades Integradas Módulo, 2003.

OLIVEIRA, L.C.; PEREZ JUNIOR, J.H.; SILVA, C.A.S. Controladoria estratégica. São Paulo: Atlas, 2002. 